\title{
Prática de higiene das mãos e crescimento bacteriano entre profissionais de saúde
}

\author{
Hand hygiene practice and bacterial growth among health professionals \\ Práctica de higiene de manos y crecimiento bacteriano entre los profesionales de la salud
}

Recebido: 10/01/2022 | Revisado: 14/01/2022 | Aceito: 21/01/2022 | Publicado: 23/01/2022

\author{
Luana Ramos Garcia \\ ORCID: https://orcid.org/0000-0003-0538-7104 \\ Universidade Federal Fluminense, Brasil \\ E-mail: luana.rgarcia@hotmail.com \\ Maithê de Carvalho e Lemos Goulart \\ ORCID: https://orcid.org/0000-0003-2764-5290 \\ Universidade Federal Fluminense, Brasil \\ E-mail: maithegoulart@gmail.com \\ Fernanda Maria Vieira Pereira Ávila \\ ORCID: https://orcid.org/0000-0003-1060-6754 \\ Universidade Federal Fluminense, Brasil \\ E-mail: fernanddamaria@hotmail.com \\ Fernanda Garcia Bezerra Góes \\ ORCID: https://orcid.org/0000-0003-3894-3998 \\ Universidade Federal Fluminense, Brasil \\ E-mail: ferbezerra@gmail.com \\ Cristiane Albuquerque de Carvalho \\ ORCID: https://orcid.org/0000-0002-3243-7966 \\ Universidade Federal Fluminense, Brasil \\ E-mail: doutoracristianecarvalho@gmail.com \\ Pedro Ruiz Barbosa Nassar \\ ORCID: https://orcid.org/0000-0002-9238-0519 \\ Universidade Federal Fluminense, Brasil \\ E-mail: pedrornassar@gmail.com
}

\begin{abstract}
Resumo
O objetivo do estudo é identificar a prática de higiene das mãos e o crescimento bacteriano de staphylococcus aureus meticilina resistente (MRSA) entre profissionais de saúde. Trata-se de um estudo observacional, transversal, com profissionais de saúde de um hospital público, entre 2019 e 2020, por meio de observação não participante da técnica de higiene das mãos e coleta para análise microbiológica. Utilizou-se Teste de Fisher, Qui-quadrado e Teste t de Student. Participaram $73(100,0 \%)$ profissionais, sendo a maioria da equipe de enfermagem. O escore médio geral obtido para a higiene das mãos foi 6,9 (DP=1,6; $\min =2$, $\max =10$; IC95\%: 6,5-7,2), denotando adesão de 57,5\% da técnica. Os escores apresentaram diferença estatística significativa para profissão e carga horária $(\mathrm{p}<0,05)$. Houve crescimento bacteriano de MRSA em 19 (26,0\%) amostras, com associação com o tempo de atuação e a profissão ( $<<0,05)$. Nenhum profissional cumpriu todas as etapas da técnica e o crescimento bacteriano foi maior entre profissionais com maior tempo de atuação e da equipe de enfermagem.
\end{abstract}

Palavras-chave: Higiene das mãos; Profissionais de saúde; Infecção hospitalar; Crescimento bacteriano.

\begin{abstract}
The aim of the study is to identify the practice of hand hygiene and the bacterial growth of methicillin-resistant staphylococcus aureus (MRSA) among healthcare professionals. This is an observational, cross-sectional study with health professionals from a public hospital, between 2019 and 2020, through non-participant observation of the hand hygiene technique and collection for microbiological analysis. Fisher's test, chi-square and Student's t test were used. $73(100.0 \%)$ professionals participated, most of them from the nursing team. The overall mean score obtained for hand hygiene was $6.9(\mathrm{SD}=1.6 ; \min =2, \max =10 ; 95 \% \mathrm{CI}: 6.5-7.2)$, denoting $57.5 \%$ of the technique. The scores showed a statistically significant difference for profession and workload $(\mathrm{p}<0.05)$. There was bacterial growth of MRSA in 19 $(26.0 \%)$ samples, associated with time of experience and profession $(\mathrm{p}<0.05)$. No professional completed all the steps of the technique and bacterial growth was greater among professionals with longer experience and the nursing staff.

Keywords: Hand hygiene; Health professionals; Hospital infection; Bacterial growth.
\end{abstract}

\section{Resumen}

El objetivo del estudio es identificar la práctica de la higiene de manos y el crecimiento bacteriano de Staphylococcus aureus resistente a la meticilina (MRSA) entre los profesionales de la salud. Se trata de un estudio observacional, transversal con profesionales de la salud de un hospital público, entre 2019 y 2020, mediante observación no participante 
de la técnica de higiene de manos y recogida para análisis microbiológico. Se utilizaron las pruebas de Fisher, chicuadrado y t de Student. Participaron $73(100,0 \%)$ profesionales, la mayoría del equipo de enfermería. La puntuación media global obtenida para la higiene de manos fue de 6,9 (DE = 1,6; $\min =2$, máx = 10; IC del 95\%: 6,5-7,2), lo que denota el $57,5 \%$ de la técnica. Los puntajes mostraron una diferencia estadísticamente significativa para la profesión y la carga de trabajo ( $\mathrm{p}<0.05)$. Hubo crecimiento bacteriano de MRSA en $19(26,0 \%)$ muestras, asociado al tiempo de experiencia y profesión $(\mathrm{p}<0,05)$. Ningún profesional completó todos los pasos de la técnica y el crecimiento bacteriano fue mayor entre los profesionales con mayor experiencia y el personal de enfermería.

Palabras clave: Higiene de manos; Profesionales de la salud; Infección hospitalaria; Crecimiento bacterial.

\section{Introdução}

As mãos são consideradas os principais meios de atuação do profissional de saúde e é por meio delas que é possível realizar os mais variados procedimentos na prática assistencial. Desta forma, a segurança do paciente está intimamente relacionada à aplicação da técnica de higiene das mãos (HM) preconizada, de maneira correta e corriqueira, bem como dos demais fatores associados às boas práticas na realização dessa medida como a falta de infraestrutura e conhecimento acerca da técnica adequada (Korb et al., 2019; Belela-Anacletoi et al., 2017).

A Agência Nacional de Vigilância Sanitária (ANVISA) publicou a RDC nº 36/2013 (Ministério da Saúde, 2013) que tornou obrigatória as ações para a segurança do paciente, incluindo o protocolo de prática de $\mathrm{HM}$ em todos os serviços de saúde e, em 2018, foi publicada uma nota técnica sobre as orientações gerais para HM nestes serviços, visando a aplicação das boas práticas estabelecidas para esse procedimento (Agência Nacional de Vigilância Sanitária [ANVISA], 2018). Ademais, vale destacar que, a falta de motivação profissional devido à excessiva jornada de trabalho, o desinteresse, a negligência e a falta de incentivo dos serviços de saúde são questões intrínsecas nessa baixa adesão e que nem sempre recebem a devida atenção por parte dos gestores (Moura et al., 2017).

Isto posto, a Organização Mundial de Saúde (OMS) implementou a Aliança Mundial para a Segurança do Paciente, na qual foram constituídas metas internacionais de segurança, incluindo a redução de Infecções Relacionadas à Assistência à Saúde (IRAS). A HM é tida então, como uma prática que deve ser promovida e incentivada nos serviços de saúde, com intenção de reduzir infecções e trazer menos danos aos pacientes, podendo ser alcançada por meio de estratégias empregadas em função da mudança de comportamento multimodal (Kilpatrick et al., 2019; Valim et al., 2019).

Cabe destacar que, os profissionais de saúde devem estar atentos quanto à técnica adequada, mas, sobretudo aos momentos em que ela deve ser realizada. Para tal, a OMS recomenda os cinco momentos para HM: antes do contato com o paciente, antes da realização de procedimento asséptico, após risco de exposição a fluídos corporais, após contato com o paciente e após contato com áreas próximas ao paciente (Farias et al., 2019). A HM também é considerada, pelo Centers for Disease Control and Prevention (CDC), como uma medida eficaz e importante na prevenção e controle de infecções, além de ser um dos pilares mais eficientes da segurança do paciente (Centers for Disease Control and Prevention [CDC], 2002; Fernandes et al., 2019).

A pele pode servir de reservatório para diferentes microrganismos, desde os mais inócuos até os mais nocivos, transmitidos por contato direto ou indireto, portanto, a microbiota das mãos, residual ou transitória, pode provocar impacto na saúde quando não removida (Bullé et al., 2016). A microbiota residente coloniza as camadas mais profundas da pele, já a transitória é mais superficialmente e sobrevive temporariamente, o que torna sua remoção mais fácil, entretanto, são microrganismos intimamente relacionados aos casos de infecção hospitalar (Palos et al., 2017).

Dentre os microrganismos transitórios das mãos dos profissionais, encontram-se o staphylococcus aureus metilcilina resistentes (MRSA), staphylococcus coagulase negativo, enterococcus faecalis e enterococcus faecium, escherichia coli, klebsiella pneumoniae, enterobacter sp, proteus mirabilis, citrobacter sp, bastonetes gram-negativos (BGN) produtores de beta- 
lactamase de expectro ampliado (BLEA), pseudomonas aeruginosa, burkolderia cepacia, acinobacter baumanii, stenotrophomonas maltophilia, entre outros (Palos et al., 2017).

O contato direto com o paciente ou com produtos e equipamentos próximos a ele, pode promover o aumento da microbiota das mãos dos profissionais e, consequentemente sua contaminação. Assim, alguns fungos e bactérias multirresistentes, como o MRSA comumente encontrado nos hospitais (Bullé et al., 2016), podem colonizar as mãos dos profissionais e se disseminarem entre os pacientes através do contato. A prática de HM reduz significativamente a transmissão destes patógenos, diminuindo a incidência de infecções preveníveis e reduzindo a morbimortalidade nos serviços de saúde (Feldhaus et al., 2018).

A forma de remoção adequada da maior parte dos microrganismos patogênicos nas mãos, ocorre por meio de fricção mecânica em toda sua superfície, utilizando água e sabão, por aproximadamente quarenta a sessenta segundos, removendo inclusive o suor, a sujidade e a oleosidade (Bullé et al., 2016). Neste sentido, três elementos são essenciais para esta prática: agente tópico com eficácia antimicrobiana, procedimento adequado ao utilizá-lo (com técnica adequada e no tempo preconizado) e adesão regular no seu uso (Agência Nacional de Vigilância Sanitária [ANVISA], 2009).

Contudo, para que esta prática seja eficiente, é indispensável a participação dos gestores, com previsão e provisão de materiais em quantidade e qualidade satisfatórios, fornecimento de infraestrutura adequada e incentivo à técnica precisa. A falta de pias com acionamento sem contato, dispensadores de sabonete líquido, álcool gel, além de toalhas de papel e lixeiras próximas ao local de assistência são exemplos de condições inadequadas que contribuem para baixa adesão às boas práticas de HM (Magnago et al., 2019).

Portanto, é preciso buscar novas evidências científicas de que a inobservância das etapas da técnica preconizada pode contribuir para a disseminação de microrganismos potencialmente patogênicos e, neste sentido, as mãos dos profissionais de saúde se tornam meio de propagação de infecções com espectro de multirresistência. A maioria dos artigos encontrados nas bases de busca versam a respeito da adesão voltada para os cinco momentos de higienizar as mãos, contudo, não analisam a adesão às etapas para a realização da técnica. Logo, o objetivo do estudo é identificar a prática de higiene das mãos e o crescimento bacteriano de MRSA entre os profissionais de saúde.

\section{Metodologia}

Trata-se de um estudo observacional, transversal, com abordagem quantitativa, que atendeu as diretrizes recomendadas pelo STrengthening the Reporting of OBservational studies in Epidemiology (STROBE) (Von Elm et al., 2007). A coleta de dados foi realizada em um hospital público, de médio porte, localizado na baixada litorânea do Rio de Janeiro, Brasil, no período de maio de 2019 a fevereiro de 2020.

A amostra do estudo se deu por conveniência com os profissionais de saúde que aceitaram participar do estudo no período de coleta de dados. Foram abordados os profissionais de saúde do cenário de estudo e incluídos aqueles que desejavam participar mediante a observação dos seguintes critérios de inclusão: profissionais da equipe de saúde que atuavam na assistência aos pacientes internados, independentemente do tempo de exercício profissional e institucional e do vínculo empregatício. Como critério de exclusão foi estabelecido: estar afastado do trabalho por licença médica e/ou outra condição em que não houvesse o retorno do profissional às suas atividades dentro do período de coleta de dados.

A coleta de dados foi realizada pelo pesquisador principal e mais três auxiliares devidamente treinados, em três etapas: 1) aplicação de questionário para caracterização dos participantes do estudo; 2) observação não participante da técnica de HM realizada pelos profissionais de saúde e 3) coleta de amostras para análise microbiológica.

1) A aplicação do questionário para caracterização dos participantes do estudo, contou com questões que envolviam aspectos individuais e profissionais. Incluiu-se como variáveis: o sexo (masculino ou feminino), profissão (profissional de 
enfermagem ou demais profissionais de saúde), tempo de atuação ( $\leq 10$ anos ou $>10$ anos), carga horária semanal (até 30 horas ou acima de 30 horas) e possuir mais de um vínculo empregatício (não ou sim).

2) A observação não participante da técnica de HM realizada pelos profissionais de saúde se deu em um único momento considerando-se a realização do procedimento com água e sabão. Após o recrutamento e aceite dos participantes, dois observadores da equipe do estudo esperavam que o profissional realizasse suas atividades e rotinas de trabalho normalmente e, quando o mesmo fosse realizar a HM, os observadores se aproximavam para visualização da técnica realizada. Embora o profissional soubesse que estava sendo observado, os pesquisadores não realizavam nenhum tipo de comunicação.

$\mathrm{O}$ instrumento utilizado para observação não participante do cumprimento da técnica realizada pelo participante compreendeu o material ilustrativo "Como higienizar as mãos com água e sabonete?" da ANVISA (Agência Nacional de Vigilância Sanitária [ANVISA], 2015). O referido material contempla as etapas para a realização da técnica, a saber: Etapa 0 molhar as mãos com água; Etapa 1 - aplique na palma da mão quantidade suficiente de sabonete líquido para cobrir todas as superfícies das mãos; Etapa 2 - ensaboe as palmas das mãos friccionando-as entre si; Etapa 3 - esfregue a palma da mão direita contra o dorso da mão esquerda, entrelaçando os dedos e vice-versa; Etapa 4 - entrelace os dedos e friccione os espaços interdigitais; Etapa 5 - esfregue o dorso dos dedos de uma mão com a palma da mão oposta, segurando os dedos, com movimento de vai-e-vem e vice-versa; Etapa 6 - esfregue o polegar esquerdo com o auxílio da palma da mão direita, utilizando-se de movimento circular e vice-versa; Etapa 7 - friccione as polpas digitais e unhas da mão direita contra a palma da mão esquerda, fazendo movimento circular e vice-versa; Etapa 8 - enxague bem as mãos com água; Etapa 9 - seque as mãos com papel toalha descartável; Etapa 10 - No caso de torneiras com contato manual para fechamento, sempre utilize papel toalha; Etapa 11 Agora suas mãos estão seguras.

3) A coleta de amostras para análise microbiológica ocorreu imediatamente após o procedimento de HM com água e sabão. Foram coletados os prints das cinco polpas digitais da mão dominante de cada profissional de saúde em placas de Petri com meio de cultura (Rosado \& Silva, 2016), para caracterização fenotípica do MRSA. Foi escolhida a mão dominante por ser a principal para manipulação de objetos e toque em superfícies e pacientes. As placas com o meio MRSA cromogênicas, da marca Laborclin ${ }^{\circledR}$, foram incubadas em estufa a $37^{\circ} \mathrm{C}$ por $24 \mathrm{~h}$. Após o período de incubação, o crescimento microbiano nas placas foi analisado segundo interpretação sugerida pelo fabricante, em relação à presença ou não de MRSA.

Os dados coletados foram inseridos em planilha eletrônica do Excel ${ }^{\circledR}$, mediante dupla digitação, processados no Programa IBM®SPSS, versão 21, e analisados por meio de estatística descritiva com medidas de tendência central (média, mediana, máximo e mínimo) e de dispersão (desvio padrão). Para avaliação da adesão à técnica de HM considerou-se um escore de 0 a 12 pontos, obtidos a partir do cumprimento das etapas contidas no material da ANVISA (ANVISA, 2015), onde a cada etapa realizada foi atribuído um ponto, sendo que quanto maior o escore, melhor o cumprimento da técnica. O Teste t de Student foi utilizado para comparar a média dos escores da técnica de HM e as variáveis individuais sexo, profissão, tempo de atuação, carga horária semanal e possuir mais de um vínculo empregatício.

Para o desfecho crescimento de MRSA (sim ou não) foram associadas às variáveis independentes relacionadas ao cumprimento de cada etapa da técnica de HM (não ou sim), além de sexo, profissão, tempo de atuação, carga horária semanal e possuir mais de um vínculo empregatício, utilizando o teste Qui-Quadrado e o teste exato de Fisher. Adotou-se p< 0,05 e intervalo de confiança de 95\% (IC 95\%).

O estudo contemplou todos os princípios éticos estabelecidos pela Resolução no 466/2012 do Conselho Nacional de Saúde (CNS) e foi aprovado pelo Comitê de Ética em Pesquisa (CEP) (parecer: 3.148.879; CAEE: 07669218.8.0000.8160). O processo de recrutamento e consentimento dos participantes do estudo ocorreu no momento da disponibilidade dos profissionais, durante o turno de trabalho, em local reservado. 


\section{Resultados}

Participaram do estudo $73(100,0 \%)$ profissionais de saúde, dentre eles, 52 (71,2\%) da equipe de enfermagem (enfermeiros e técnicos de enfermagem) e os demais 21 (28,8\%) profissionais das diversas áreas de saúde (medicina, fisioterapia, nutrição, fonoaudiologia e radiologia). A média de idade foi de 46,3 anos (DP = 9,5; Mínimo = 27; Máximo = 67), com predominância do sexo feminino, $56(76,7 \%)$.

Com relação à escolaridade, 43 (58,9\%) possuíam nível superior, 27 (36,9\%) curso técnico e, além da graduação, dois $(2,7 \%)$ participantes cursaram mestrado e um $(1,3 \%)$ doutorado. Quanto ao vínculo empregatício, $51(69,8 \%)$ profissionais possuíam emprego em mais de uma instituição de saúde (Tabela 1). A maior parte dos participantes atua há mais de 10 anos na área, 54(73,9\%), com média de 17,4 anos (DP = 9,0) e carga horária de trabalho acima de 30 horas semanais, com média de 36,7 horas $(\mathrm{DP}=11,9)$.

Tabela 1 - Caracterização dos participantes quanto ao sexo, profissão, tempo de atuação, carga horária, quantidade de vínculo empregatício e setor de trabalho. Rio das Ostras, RJ, Brasil, 2020.

\begin{tabular}{lc}
\hline \multicolumn{1}{c}{ Variáveis Individuais } & $\mathbf{N}(\boldsymbol{\%})$ \\
\hline Sexo & $17(23,3)$ \\
Masculino & $56(76,7)$ \\
Feminino & \\
Profissão & $52(71,3)$ \\
Profissional de enfermagem & $21(28,7)$ \\
Demais profissionais de saúde & \\
Tempo de atuação (anos) & $19(26,1)$ \\
$\leq 10$ anos & $54(73,9)$ \\
$>10$ anos & \\
Carga horária & $24(32,8)$ \\
Até 30 horas & $49(67,2)$ \\
Acima de 30 horas & \\
Mais de um vínculo empregatício & $22(30,2)$ \\
Não & $51(69,8)$ \\
Sim & \\
Setor & $4(5,5)$ \\
Centro de Imagem & $14(19,2)$ \\
Centro de Terapia Intensiva & $21(28,8)$ \\
Enfermaria & $8(10,9)$ \\
Nutrição & $18(24,7)$ \\
Obstetrícia & $7(9,6)$ \\
Pediatria & $1(1,3)$ \\
Radiologia &
\end{tabular}

Fonte: Autores.

Neste estudo, os $73(100,0 \%)$ profissionais não cumpriram todas as etapas da técnica preconizada pela ANVISA. Nas etapas preconizadas, a etapa 1 teve a maior adesão, 69 (94,5\%), e a etapa 5 a menor adesão dos profissionais de saúde, 6 (8,2\%). Embora a etapa 5 da técnica de HM tenha apresentado menor adesão dos profissionais de saúde, na comparação das etapas com o crescimento bacteriano de MRSA, observou-se associação estatística significante $(p=0,031)$ com a etapa 0 , que representa o 
Research, Society and Development, v. 11, n. 2, e20011225571, 2022

(CC BY 4.0) | ISSN 2525-3409 | DOI: http://dx.doi.org/10.33448/rsd-v11i2.25571

momento de molhar as mãos. Isto é, os participantes que cumpriram a etapa de molhar as mãos, apresentaram menor crescimento das colônias de MRSA (Tabela 2).

Tabela 2: Associação das etapas da técnica de higiene das mãos e o crescimento de MRSA. Rio de Janeiro, RJ, Brasil, 2020.

\begin{tabular}{|c|c|c|c|}
\hline \multirow{2}{*}{$\begin{array}{c}\text { Etapas e Cumprimento da Técnica de } \\
\text { Higiene das Mãos }\end{array}$} & \multicolumn{2}{|c|}{ Crescimento de MRSA } & \multirow[b]{2}{*}{ Valor de $p$} \\
\hline & $\begin{array}{l}\text { Não } \\
\text { n }(\%)\end{array}$ & $\begin{array}{c}\text { Sim } \\
\text { n }(\%)\end{array}$ & \\
\hline \multicolumn{4}{|l|}{ Etapa 0} \\
\hline Não & $14(93,3)$ & $1(6,7)$ & $0,031^{(*)}$ \\
\hline Sim & $40(69,0)$ & $18(31,0)$ & \\
\hline \multicolumn{4}{|l|}{ Etapa 1} \\
\hline Não & $2(50,0)$ & $2(50,0)$ & $0,416^{(*)}$ \\
\hline Sim & $52(75,4)$ & $17(24,6)$ & \\
\hline \multicolumn{4}{|l|}{ Etapa 2} \\
\hline Não & $11(73,3)$ & $4(26,7)$ & $1^{(*)}$ \\
\hline Sim & $43(74,1)$ & $15(25,9)$ & \\
\hline \multicolumn{4}{|l|}{ Etapa 3} \\
\hline Não & $11(78,6)$ & $3(21,4)$ & $0,854^{(*)}$ \\
\hline Sim & $43(72,9)$ & $16(27,1)$ & \\
\hline \multicolumn{4}{|l|}{ Etapa 4} \\
\hline Não & $18(69,2)$ & $8(30,8)$ & $0,492^{(* *)}$ \\
\hline Sim & $36(76,6)$ & $11(23,4)$ & \\
\hline \multicolumn{4}{|l|}{ Etapa 5} \\
\hline Não & $49(73,1)$ & $18(26,9)$ & $1^{(*)}$ \\
\hline Sim & $5(83,3)$ & $1(16,7)$ & \\
\hline \multicolumn{4}{|l|}{ Etapa 6} \\
\hline Não & $26(70,3)$ & $11(29,7)$ & $0,465^{(* *)}$ \\
\hline Sim & $28(77,8)$ & $8(22,2)$ & \\
\hline \multicolumn{4}{|l|}{ Etapa 7} \\
\hline Não & $30(73,2)$ & $11(26,8)$ & $0,860^{(* *)}$ \\
\hline Sim & $24(75,0)$ & $8(25,0)$ & \\
\hline \multicolumn{4}{|l|}{ Etapa 8} \\
\hline Não & $7(70,0)$ & $3(30,0)$ & $1^{(*)}$ \\
\hline Sim & $47(74,6)$ & $16(25,4)$ & \\
\hline \multicolumn{4}{|l|}{ Etapa 9} \\
\hline Não & $18(78,3)$ & $5(21,7)$ & $0,571^{(* *)}$ \\
\hline Sim & $36(72,0)$ & $14(28,0)$ & \\
\hline \multicolumn{4}{|l|}{ Etapa 10} \\
\hline Não & $46(78,0)$ & $13(22,0)$ & $0,249^{(*)}$ \\
\hline Sim & $8(57,1)$ & $6(42,9)$ & \\
\hline \multicolumn{4}{|l|}{ Etapa 11} \\
\hline Não & $44(72,1 \%)$ & $17(27,9)$ & $0,720^{(*)}$ \\
\hline Sim & $10(83,3 \%)$ & $02(16,7 \%)$ & \\
\hline
\end{tabular}

Nota: Teste Estatístico: ${ }^{(*)}$ Teste Exato de Fisher ${ }^{(* *)}$ Qui-Quadrado. Fonte: Autores. 
O escore médio geral para a prática de HM obtido foi 6,9 (DP= 1,6, Mínimo = 2, Máximo = 10, IC95\%: 6,5-7,2), denotando adesão de 57,5\% ao procedimento de HM. Na comparação das médias dos escores entre as variáveis individuais, houve diferença estatística significativa para profissão $(\mathrm{p}=0,015)$ e para a carga horária $(\mathrm{p}=0,012)$. Os profissionais de enfermagem apresentaram os escores mais baixos quando comparados aos demais profissionais de saúde e os participantes que possuíam carga horária semanal acima de 30 horas, de igual maneira, apresentaram escores mais baixos para HM quando comparados àqueles que cumpriam até 30 horas semanais (Tabela 3).

Tabela 3 - Comparação entre o escore da técnica de higiene das mãos e as variáveis individuais dos profissionais de saúde (n= 73). Rio de Janeiro, RJ, Brasil, 2020.

\begin{tabular}{lcccccc}
\hline \multicolumn{1}{c}{ Variáveis } & $\mathbf{n}$ & $\begin{array}{c}\text { Média } \\
\text { Escore }\end{array}$ & IC 95 & DP & $\begin{array}{c}\text { Valor do } \\
\text { teste }\end{array}$ & Valor de $\boldsymbol{p}$ \\
\hline Sexo & 17 & 7,1 & $6,5-7,9$ & 1,4 & $\mathrm{t}=-0,87$ & 0,389 \\
Masculino & 56 & 6,8 & $6,3-7,3$ & 1,7 & & \\
Feminino & & & & & & \\
Profissão & 52 & 6,6 & $6,1-7,1$ & 1,6 & $\mathrm{t}=-2,51$ & $\mathbf{0 , 0 1 5}$ \\
Profissional de enfermagem & 21 & 7,6 & $6,9-8,3$ & 1,5 & & \\
Demais profissionais de saúde & & & & & & \\
Tempo de atuação (anos) & 19 & 6,3 & $5,5-7,2$ & 1,7 & $\mathrm{t}=-1,59$ & 0,122 \\
$\leq 10$ anos & 54 & 7,0 & $6,6-7,5$ & 1,6 & & \\
$>10$ anos & & & & & & \\
Carga horária & 24 & 7,6 & $6,9-8,4$ & 1,9 & $\mathrm{t}=-2,61$ & $\mathbf{0 , 0 1 2}$ \\
Até 30 horas & 49 & 6,5 & $6,1-6,9$ & 1,4 & & \\
Acima de 30 horas & & & & & & \\
Mais de um vínculo empregatício & 22 & 6,4 & $5,6-7,3$ & 1,9 & $\mathrm{t}=-1,40$ & 0,168 \\
Não & 51 & 7,0 & $6,7-7,5$ & 1,5 & & \\
Sim & & & & & & \\
\hline
\end{tabular}

Nota: *Teste Estatístico: Teste t de Student. Fonte: Autores.

Destaca-se que houve crescimento bacteriano de MRSA em 19 (26,0\%) amostras coletadas. Na associação das variáveis com o crescimento do MRSA nas amostras, houve significância estatística entre o tempo de atuação $(p=0,030)$ e a profissão ( $p=$ 0,041), ou seja, maior crescimento bacteriano nas mãos dos profissionais com maior tempo de atuação e entre profissionais de enfermagem (Tabela 4). 
Tabela 4- Associação do crescimento bacteriano de MRSA e as variáveis individuais dos profissionais de saúde (n= 73). Rio de Janeiro, RJ, Brasil, 2020.

\begin{tabular}{|c|c|c|c|}
\hline \multirow{2}{*}{ Variáveis } & \multicolumn{3}{|c|}{ Crescimento MRSA } \\
\hline & $\begin{array}{c}\text { Sim } \\
\mathbf{n}(\%)\end{array}$ & $\begin{array}{l}\text { Não } \\
\text { n(\%) }\end{array}$ & Valor de $p$ \\
\hline \multicolumn{4}{|l|}{ Sexo } \\
\hline Masculino & $7(36,9)$ & $10(18,5)$ & $0,123^{*}$ \\
\hline Feminino & $12(63,1)$ & $44(81,5)$ & \\
\hline \multicolumn{4}{|l|}{ Profissão } \\
\hline Profissional de enfermagem & $17(89,5)$ & $35(64,8)$ & $0,041 * *$ \\
\hline Demais profissionais de saúde & $2(10,5)$ & $19(35,2)$ & \\
\hline \multicolumn{4}{|l|}{ Tempo de atuação } \\
\hline$\leq 10$ anos & $9(47,4)$ & $10(18,5)$ & $\mathbf{0 , 0 3 0} *$ \\
\hline$>10$ anos & $10(52,6)$ & $44(81,5)$ & \\
\hline \multicolumn{4}{|l|}{ Carga horária } \\
\hline Até 30 horas & $3(15,8)$ & $21(38,9)$ & $0,065 * *$ \\
\hline Acima de 30 horas & $16(84,2)$ & $33(61,1)$ & \\
\hline \multicolumn{4}{|c|}{ Mais de um vínculo empregatício } \\
\hline Não & $9(47,4)$ & $13(24,1)$ & $0,057 * *$ \\
\hline Sim & $10(52,6)$ & $41(75,9)$ & \\
\hline
\end{tabular}

Nota: Teste Estatístico: *Teste Exato de Fisher **Qui-Quadrado. Fonte: Autores.

\section{Discussão}

Este estudo identificou a adesão de 57,5\% da técnica de HM preconizada pela ANVISA e o crescimento de MRSA nas amostras coletadas das mãos dos profissionais de saúde, após realizarem a HM com água e sabão. Apesar da importância da HM na prevenção e controle das infecções, diversos profissionais de saúde mantém uma conduta pouco resolutiva diante da real situação encontrada (Zottele et al., 2017).

Em consonância com os dados dessa pesquisa, uma investigação mostrou que a taxa de adesão às oportunidades de HM foi de $29 \%$ entre os profissionais de saúde da área oncológica, resultando em uma assistência de saúde classificada como sofrível e indesejada (Llapa-Rodrígue et al., 2018). Ainda, outro estudo realizado entre 56 enfermeiros em um hospital em João Pessoa, revelou que todos acreditam na importância e eficiência da HM, admitem que as mãos são consideradas agentes indutores de infecção e 64\% deles asseguraram praticar a técnica corretamente. Entretanto, apesar da percepção adequada, a taxa de adesão a oportunidades de HM encontrava-se extremamente baixa, em torno de $8 \%$ (Oliveira et al., 2019).

Em relação às categorias profissionais na presente pesquisa, há destaque para os profissionais de enfermagem que apresentaram os escores mais baixos para a técnica de HM. Este dado diverge da literatura encontrada em que foram comparadas as categoriais profissionais de um hospital oncológico no estado de Sergipe, e encontrou-se que, especificamente, os enfermeiros tiveram maior taxa de adesão a HM em relação aos médicos (Oliveira et al., 2019).

Os resultados apontaram menores escores da técnica de higiene das mãos nos profissionais de saúde que fazem mais de 30 horas semanais de trabalho. Corroborando com este dado, um estudo realizado em uma unidade de transplante de células- 
tronco no University Hospital Basel, Suíça, em que as oportunidades de HM foram identificadas eletronicamente nos prontuários, a partir dos cinco momentos para higiene das mãos da OMS, verificou a alta carga horária de trabalho como motivo de menor aderência ao procedimento de lavar as mãos (Llapa-Rodrígue et al., 2018).

A adesão inadequada à técnica pode ser entendida como um fator de negligência na assistência, pelo fato de não incluir o conhecimento teórico em sua prática diária e por apresentar somente a intenção de lavar as mãos. Tal fator pode provocar danos irreparáveis à saúde da população sob os cuidados destes profissionais (Oliveira et al., 2019; Scheithauer et al., 2017).

O conhecimento teórico perpassa também pelo procedimento da técnica, que se torna inadequado quando há inobservância das etapas, como evidenciado neste estudo em que houve menor adesão na etapa 5, referente a esfregar o dorso dos dedos de uma mão com a palma da mão oposta, segurando os dedos, com movimento de vai-e-vem e vice-versa. Além disto, pode-se observar que já na etapa inicial da técnica referente a molhar as mãos, houve associação com o menor crescimento bacteriano, contudo não foi encontrado resultados semelhantes na literatura científica.

Cabe destacar que, a inobservância do passo-a-passo da técnica de HM pode influenciar na remoção mecânica de microrganismos e consequentemente no crescimento bacteriano das amostras que são coletadas, visto que a HM visa remover a flora transitória que coloniza as camadas superficiais da pele (ANVISA, 2009). Os resultados de crescimento de colônias de MRSA nas amostras do presente estudo indicam que há possibilidade de transmissão desses microrganismos patogênicos através das mãos destes profissionais de saúde, o que tende a ser um fator importante na ocorrência das IRAS.

Tal dado também foi observado em um estudo com 51 profissionais de saúde em Unidades de Terapia Intensiva, em que a HM foi deficiente e negligenciada culminando no crescimento de bactérias em $60 \%$ das amostras coletadas. Nesta mesma pesquisa, foram isoladas 32 bactérias Gram-positivas e negativas nas amostras coletadas das mãos dos profissionais, sendo as enterobactérias as mais frequentes. Além disto, foram encontradas bactérias multirresistentes, incluindo MRSA e, também, bactérias de expectro estendido de atividade da $\beta$-lactamases (ESBL) (Soares et al., 2019).

Entretanto, se comparado o tempo de atuação profissional dos participantes deste estudo, houve maior crescimento de colônias MRSA nas amostras dos profissionais com maior tempo de atuação. Em uma pesquisa que avaliou a adesão a HM nos cinco momentos preconizados, pelos profissionais da equipe de enfermagem de cuidados intensivos, identificou-se que $76,4 \%$ dos profissionais com atuação profissional entre 1 a 10 anos apresentaram baixa taxa de adesão a HM, o que difere dos achados atuais, com destaque para momentos antes da realização de procedimento asséptico e antes do contato com paciente (Vasconcelos et al., 2018).

Ainda no estudo realizado na terapia intensiva, foi encontrado que a maioria dos participantes eram mulheres, com idade entre 30 e 39 anos, que realizavam a técnica de forma deficitária, resultando na adesão de aproximadamente $48 \%$ dos momentos de higienizar as mãos (Vasconcelos et al., 2018). De igual maneira e corroborando com os achados do presente estudo, 80\% dos enfermeiros participantes de uma pesquisa realizada em Portugal eram do sexo feminino, característica própria da profissão. Ainda, quando questionadas sobre a sua própria adesão ao procedimento, cerca de $90 \%$ das 50 enfermeiras, consideram respeitar as recomendações existentes sobre higiene das mãos, realizando-a em 75\% ou mais dos momentos preconizados (Graveto et al., 2018).

Todavia, a baixa adesão à prática de HM tem sido observada em diversas investigações, assim, fomentando a busca pelo aprimoramento da técnica e redução das IRAS, contribuindo para a segurança do paciente e também do profissional de saúde. Desse modo, uma pesquisa realizada em 11 casas de repouso em Taiwan, mostrou a eficácia na implementação da estratégia de HM da OMS, aumentando a taxa em 5,8\% e a redução da taxa de densidade geral de infecção em 0,5 por 10.000 residentes-dia após intervenção (Lai et al., 2019). Outro estudo constatou também uma melhora significativa desta prática entre médicos e enfermeiros, através de uma intervenção multimodal em hospitais terciários em Niigata, Japão, elevando a adesão em 11,2\% após intervenção, destacando-se melhores taxas entre os enfermeiros (Saitoh et al., 2020). 
A vista disso, estudos mostram que é necessário reformular esta prática nos serviços de saúde, no intuito de aumentar a adesão à HM através de mudança na cultura institucional e no comportamento dos profissionais, garantindo assim, uma técnica completa, desde o momento certo, local certo e passo-a-passo adequado para propiciar um atendimento seguro (Silva et al., 2018; Phan et al., 2018). Destaca-se que, para diminuir as taxas de IRAS vale incluir estratégias que promovam mudanças em diversos aspectos, como educação continuada, monitoramento da adesão a HM, manutenção e instalação de equipamentos necessários às boas práticas de HM (Soares et al., 2019; Souza et al., 2018).

Entende-se como limitação do estudo, o método utilizado para a coleta das amostras biológicas e a escolha de um único momento de higienizar as mãos. A utilização de print das polpas digitais em placa de meio de cultura seletivo pode gerar a perda de crescimento bacteriano. Além disso, ressalta-se que a coleta de dados foi interrompida, dada a exposição dos pesquisadores em ambiente hospitalar, com o início da pandemia de COVID-19. Apesar desses aspectos, os dados da pesquisa foram contundentes para evidenciar o crescimento de bactérias MRSA nas mãos dos profissionais, o que leva a reflexões sobre a importância de medidas gerenciais e assistenciais para melhorar a adesão a HM, inclusive durante a pandemia.

\section{Conclusão}

Neste estudo, nenhum profissional cumpriu todas as etapas da técnica preconizada pela ANVISA. Houve maior crescimento bacteriano nas mãos dos profissionais com maior tempo de atuação e entre profissionais de enfermagem.

Identificou a presença de bactérias multirresistentes do fenótipo MRSA nas mãos dos profissionais de saúde imediatamente após a realização da técnica. Nessa vertente, há preocupação em relação a prática assistencial, exposição dos pacientes à microrganismos potencialmente patogênicos, por meio das mãos dos profissionais de saúde.

Acredita-se que, os dados elencados por esse estudo, possam dar subsídio para novas ações educativas junto à equipe multiprofissional, de forma a repercutir positivamente na adesão a técnica correta de HM. Ressalta-se que, é imprescindível uma intervenção que apresente a relação direta da adesão a técnica e remoção mecânica de microrganismos potencialmente patogênicos, contribuindo assim, para o controle de infecções relacionadas à assistência à saúde. Além de ratificar a necessidade de serem avaliados aspectos referentes à carga horária de trabalho dos profissionais de saúde.

Sugere-se novos estudos que avaliem à adesão a técnica de higiene das mãos, considerando inclusive o contexto da pandemia de Covid-19 e a ênfase dada neste período à esta técnica em especial.

\section{Referências}

Agência Nacional de Vigilância Sanitária. (2009). Segurança do Paciente em Serviços de Saúde: Higienização das Mãos / Agência Nacional de Vigilância Sanitária. https://www20.anvisa.gov.br/segurancadopaciente/index.php/publicacoes/item/seguranca-do-paciente-higienizacao-das-maos.

Agência Nacional de Vigilância Sanitária. (2015). Manual de Referência Técnica para a Higiene das Mãos. https://www20.anvisa.gov.br/segurancadopaciente/index.php/publicacoes/item/manual-de-referencia-tecnica-para-a-higiene-das-maos.

Agência Nacional de Vigilância Sanitária. (2018). Nota Técnica Nº1/2018 GVIMS/GGTES/ANVISA: Orientações gerais para higiene das mãos em serviços de saúde. http://portal.anvisa.gov.br/documents/33852/271858/NOTA+T\%C3\%89CNICA+N\%C2\%BA01-2018+GVIMS-GGTES-ANVISA/ef1b8e18-a36f$41 \mathrm{ae}-84 \mathrm{c} 9-53860 \mathrm{bc} 2513 \mathrm{f}$.

Belela-Anacletoi, A. S. C., Peterlinii, M. A. S., \& Pedreira, M. L. G. (2017). Higienização das mãos como prática do cuidar: reflexão acerca da responsabilidade profissional. Rev Bras Enferm, 70(2), 442-5. http://dx.doi.org/10.1590/0034-7167-2016-0189.

Bullé, D. J., Potter, C., Arnhold, G. H. O., Santos, C. E., Arcadepani, T., Reuter, C. P., \& Renner, J. D. P. (2016). Staphylococcus aureus methicillin-resistant in healthcare professionals. Revista De Enfermagem Da UFSM, 6(2), 198-205. http://dx.doi.org/10.5902/2179769216753.

Centers for Disease Control and Prevention. (2002). Guideline for Hand Hygiene in Health-Care Settings: Recommendations of the Healthcare Infection Control Practices Advisory Committee and the HICPAC/SHEA/APIC/IDSA Hand Hygiene Task Force. https://www.cdc.gov/mmwr/PDF/rr/rr5116.pdf.

Farias, M. E. L., Gonçalves, J. S., \& Jesus, I. S. (2019). Adesão à higiene das mãos antes e após intervenções educativas do dia mundial para higienização das mãos em um hospital universitário. REAS, 11(16), e1354. http://dx.doi.org/10.25248/reas.e1354.2019. 
Feldhaus, C., Loro, M.M., Rutke, T. C. B., Matter. O. S., Kolankiewicz, A. C. B., \& Stumm, E. M. F. (2018). Knowledge of nursing and physiotherapy students on Hand Hygiene. Rev Min Enferm, 22, e-1096. http://dx.doi.org/10.5935/1415-2762.20180026.

Fernandes, D. R., Braga, F. T. M. M., Silveira, R. C. C. P., \& Garbin, L. M. (2019). Hand hygiene: knowledge and skill of caregivers in the hematopoietic stem cell transplantation. Rev Bras Enferm, 72(6), 1653-61. http://dx.doi.org/10.1590/0034-7167-2018-0788.

Graveto, J. M., Santos, C. S., Costa, O. S., Fernandes, E., Alarico, S., Osório, N., Albano, H., \& Oliveira, V. (2018). Hand hygiene management among nurses: collective health challenges. Rev. Bras. Enferm, 71(Supp11), 562-567. http://dx.doi.org/10.1590/0034-7167-2017-0538

Kilpatrick, C., Bourqui, L., Peters, A., Guitart, C., Allegranzi, B., \& Pittet, D. (2019). Hand hygiene: Sounds easy, but not when it comes to implementation. J Infect Public Health, 12(3), 301-3. http://dx.doi.org/10.1016/j.jiph.2019.04.008.

Korb. J. P. K., Jezewski, G., Aozane, F., Feldhaus, C., Kolankiewicz, A. C. B., \& Loro, M. M. (2019). Knowledge of Hand Hygiene in the Perspective of Nursing Professionals from an Emergency Service. Rev Pesqui: Cuid Fundam, 11(2), 517-523. http://dx.doi.org/10.9789/2175-531.2019.v11i2.517-523.

Lai, C., Lu, M., Tang, H., Chen, Y., Wu, Y., Chiang, H., Li-Hung, W., Wen-Chien, K., Po-Ren, H., \& Yu-Hui, C. (2019). Implementation of a national quality improvement program to enhance hand hygiene in nursing homes in taiwan. $J$ Microbiol Immunol Infect, 52(2), 345-351. http://dx.doi.org/10.1016/j.jmii.2018.09.007.

Llapa-Rodrígue, E. O., Oliveira, J. K. A., Menezes, M. O., Silva, L. S. L., Almeida, D. M., \& Neto, D. L. (2018). Health professionals' adhesion to hand hygiene. Rev enferm UFPE on line, 12(6), 1578-85. http://dx.doi.org/10.5205/1981-8963-v12i6a230841p1578-1585-2018.

Magnago, T. S. B. S., Ongaro, J. D., Greco, P. B. T., Lanes, T. C., Zottele, C., Gonçalves, N. G., \& Andolhe, R. (2019). Infrastructure for hand hygiene in a teaching hospital. Rev. Gaúcha Enferm, 40(esp), e20180193. http://dx.doi.org/10.1590/1983-1447.2019.20180193.

Ministério da Saúde. (2013). Agência Nacional de Vigilância Sanitária. Resolução - RDC No 36 , de 25 de julho de 2013. https://bvsms.saude.gov.br/bvs/saudelegis/anvisa/2013/rdc0036_25_07_2013.html.

Moura, P.M.M., Tristão, F.S., Echevarría-Guanilo, M.E., \& Porto, A. R. (2017). Evaluation of hospital infrastructure for hygienization of hands. Rev enferm UFPE on line, 11(Supl.12), 5289-96. http://dx.doi.org/10.5205/1981-8963-v11i12a22884p5289-5296-2017.

Oliveira, M. A., Leuthier, R. M., Oliveira J; R; F., Leite, M. A. P., Fernandes, L. G. A., Santos, A. F., Albuquerque, K. F., \& Correia, K, G. (2019). Hand hygiene: das mãos: knowledge and attitudes of healthcare professionals. Rev enferm UFPE on line, 13, e236418. http://dx.doi.org/10.5205/19818963.2019.236418

Palos, M. A. P., Silva, D. V. B., Gir, E., Canini, S. R. M. S., Anders, P. S., Leão, L. S. N. O., \& Pimenta, F. C. (2017). Microbiota das mãos de mães e de profissionais de saúde de uma maternidade de Goiânia. Rev. Eletr. Enferm, 11(3), 573-8. https://doi.org/10.5216/ree.v11.47111.

Phan, H. T., Tran, H. T. T., Tran, H. T. M., Dinh, A. P. P., Ngo, H. T., Haglow, J. T., \& Gordon, C. J. (2018). An educationalintervention to improve hand hygiene compliance in Vietnam. BMC Infect Dis, 18(1), 116. http://dx.doi.org/10.1186 / s12879-018-3029-5.

Rosado, A. V., \& Silva, F. L. (2016). A avaliação da eficácia de antissépticos nas mãos dos profissionais de saúde. Rev. Saúde em Foco, 3(1), 01-19. http://www4.unifsa.com.br/revista/index.php/saudeemfoco/article/view/949\#: :text=Resultou\%20em\%20superioridade\%20da\%20clorexidina,triclosan\%20co $\mathrm{m} \% 2070 \% 2 \mathrm{C} 59 \% 25$.

Saitoh, A., Sato, K., Magara, Y., Osaki, K., Narita, K., Shioiri, K., Fowler, K., David, R., \& Sanjay,S. (2020). Improving Hand Hygiene Adherence in Healthcare Workers Before Patient Contact: A Multimodal Intervention in Four Tertiary Care Hospitals in Japan. J. Hosp. Med, 15(5), 262-7. http://dx.doi.org/10.12788/jhm.3446.

Scheithauer, S., Batzer, B., Dangel, M., Passweg, J., \& Widmer, A. (2017). Workload even affects hand hygiene in a highly trained and well-staffed setting: a prospective 365/7/24 observational study. J Hosp Infect, 97(1), 11-6. http://dx.doi.org/10.1016/j.jhin.2017.02.013.

Silva, B. R., Carreiro, M. A., Simões, B.F. T., \& Paula, D. G. (2018). Monitoring hand hygiene adherence in an intensive care unit. Rev enferm UERJ, 26, e33087. http://dx.doi.org/10.12957/reuerj.2018.33087.

Soares, M. A., Rodrigues, N. M., Menezes, M. R. O., Gerace, D. N., Duarte, C. M., Brandão, P. M., \& Borges, L. F. A. (2019). Multidrug-resistant microorganisms in Intensive Care Units hands of health care workers. Int J Infect Control, 9(3), 87-192. http://dx.doi.org/10.17058/reci.v9i3.12674.

Souza, L. M. B., Alievi, M. F., Piasentin, C. Z., Bandeira, V. A. C., Loro, M. M., Stumm, E. M. F., \& Kolankiewicz, A. C. B. (2018). Analysis of the knowledge of nursing professionals in relation to hygienization of hands. R Epidemiol Control Infec, 8(2), 142-149. http://dx.doi.org/10.17058/reci.v8i2.11199.

Valim, M. D., Rocha, I. L. S., Souza, T. P. M., Cruz, Y. A., Bezerra, T. B., \& Baggio, E. (2019). Efficacy of the multimodal strategy for Hand Hygiene compliance: an integrative review. Rev Bras Enferm, 72(2), 578-92. http://dx.doi.org/10.1590/0034-7167-2018-0584

Vasconcelos, R. O., Alves, D. C. I., Fernandes, L. M., \& Oliveira, J. L. C. (2018). Adhesión a la higiene de las manos por el equipo de enfermería en la unidad de cuidados intensivos. Rev enfermería global, 17(2), 430-476. http://dx.doi.org/10.6018/eglobal.17.2,.284131

Von Elm, E., Altman, D. G., Egger, M., Pocock, S. J., Gotzsche, P. C., \& Vandenbroucke, J. P. (2007ᄀ) The Strengthening the Reporting of Observational Studies in Epidemiology (STROBE) Statement: guidelines for reporting observational studies. Ann Intern Med, 147(8), 573-7. http://dx.doi.org/10.7326/00034819-147-8-200710160-00010.

Zottele, C., Magnago, T. S. B. S., Dullius, A. I. S., Kolankiewicz, A. C. B., \& Ongaro, J. D. (2017). Hand hygiene compliance of healthcare professionals in an emergency department. Rev Esc Enferm USP, 51, e03242. http://dx.doi.org/10.1590/s1980-220x2016027303242. 